\title{
EFICÁCIA DE TECNOLOGIAS DE MILHO Bt NO MANEJO DE LEPIDÓPTEROS-PRAGAS
}

\author{
HALLISON VERNISIO VERTUAN ${ }^{1,2}$, JOSÉ ROBERTO SALVADORI ${ }^{1}$ \\ WLADECIR SALLES DE OLIVEIRA² e GERALDO UBIRAJARA BERGER ${ }^{2}$
}

\author{
'Programa de Pós-Graduação em Agronomia, Faculdade de Agronomia e Medicina Veterinária, \\ Universidade de Passo Fundo-RS, hallison.vertuan@monsanto.com, salvadori@upf.br \\ ${ }^{2}$ Monsanto do Brasil Ltda., São Paulo,SP,wladecir.s.oliveira@monsanto.com,geraldo.u.berger@monsanto.com
}

$\overline{\text { Revista Brasileira de Milho e Sorgo, v.16, n.1, p. 22-29, } 2017}$

\begin{abstract}
RESUMO - Spodoptera frugiperda e Diatraea saccharalis estão entre as principais pragas da cultura do milho, e suas injúrias podem acarretar diminuição do rendimento de grãos. Com o advento do milho Bt, são necessários estudos sobre estratégias de controle, para utilização no manejo integrado dessas pragas. Experimentos foram conduzidos em campo em quatro locais do Brasil na safra 2010/2011, com o objetivo de avaliar a eficácia de híbridos de milho geneticamente modificados contendo os eventos Bt MON 810, MON 89034 e MON $89034 \times$ TC1507 × NK603, no manejo de $S$. frugiperda e $D$. saccharalis. Foram realizadas avaliações de injúrias foliares em quatro tempos distintos, utilizandose escala, número de orifícios em colmos e avaliação do rendimento de grãos. As injúrias foliares ocasionadas por $S$. frugiperda foram menores nos híbridos com os eventos MON 89034 e MON $89034 \times$ TC1507 × NK603, apresentando notas de injúrias entre 0 a 1,5, e dependendo do estádio de avaliação e local diferiram significativamente do evento MON 810. Os híbridos geneticamente modificados também tiveram menores injúrias no colmo ocasionadas por $D$. saccharalis. Considerando a média dos campos experimentais, os híbridos com evento Bt apresentaram um rendimento significativamente superior ao convencional, na ordem de 750 a $900 \mathrm{~kg} / \mathrm{ha}$.
\end{abstract}

Palavras-chave: Spodoptera frugiperda, Diatraea saccharalis, manejo de pragas.

\section{EFFICACY OF Bt MAIZE TECHNOLOGIES IN LEPIDOPTERAN PESTS MANAGEMENT}

\begin{abstract}
Spodoptera frugiperda and Diatraea saccharalis are the main maize pests and their injuries may cause yield reduction. The advent of Bt maize show that studies are required to evaluate tactical of control within integrated pest management. Field trials were conducted in four locations in Brazil during crop season 2010/2011, in order to evaluate the effectiveness of genetically modified maize hybrids containing the Bt events MON 810, MON 89034 and MON $89034 \times$ NK603 $\times$ TC1507, in management of $S$. frugiperda and D. saccharalis. Leaf injuries were performed in four different times, using scale, number of holes and yield evaluation. Leaf injuries caused by S. frugiperda were lower in maize hybrids expressing the events MON 89034 and MON $89034 \times$ TC1507 $\times$ NK603 with rates between 0 to 1.5, depending on evaluation stage, and location differed significantly from MON 810 event. The genetically modified maize hybrids also reduced stalk injuries caused by D. saccharalis. Considering the average of the experimental fields, the Bt hybrids presented a significantly higher yield than the conventional in the range of 750 to $900 \mathrm{~kg} / \mathrm{ha}$.
\end{abstract}

Keywords: Spodoptera frugiperda, Diatraea saccharalis, pest management. 
Dentre as pragas que atacam o milho, a lagarta Spodoptera frugiperda (J. E. Smith, 1797) (Lepidoptera: Noctuidae) se destaca como a mais importante para a cultura no Brasil (Cruz, 2009). Em termos de injúrias e danos, na ausência de manejo, a praga chega a destruir completamente o cartucho (Gallo et al., 2002), atacando espigas e colmos, acarretando perdas no rendimento de grãos na ordem de $15 \%$ a $34 \%$ (Lima et al., 2010). Outra praga de importância na cultura do milho é a lagarta Diatraea saccharalis (Fabricius, 1794) (Lepidoptera: Crambidae), que ataca colmos abrindo galerias, dificultando a translocação de fotoassimilados e predispondo as plantas ao tombamento por ação do vento, podendo causar perdas na produção de até 39\% (Pinto et al., 2004).

A introdução de culturas transgênicas que expressam genes oriundos da bactéria Bacillus thuringiensis (Bt), em sistemas de produção agrícola, possibilitou que programas de Manejo Integrado de Pragas (MIP) fossem mais eficientes, principalmente com a diminuição da dependência do controle químico (Sanahuja et al., 2011). O uso da tecnologia Bt no milho tem se destacado como uma das principais ferramentas no manejo dessas pragas. Diversos autores relataram a eficácia e os benefícios do milho Bt no manejo de pragas na cultura do milho (Edgerton et al., 2012; James, 2014; Klümper \& Qaim, 2014; Michelotto et al., 2011; Waquil et al., 2013). Além disso, foi verificado rendimento de grãos superior na ordem de 32\% em alguns eventos de milho Bt quando comparado a híbridos convencionais (Waquil et al., 2002).

Apesar da adoção das tecnologias Bt no manejo das pragas-alvo, o uso delas sem as práticas de Manejo de Resistência de Insetos (MRI), como a implementação das áreas de refúgio, pode limitar a durabilidade da eficácia de controle de pragas ao longo do tempo, uma vez que o uso de culturas Bt em ambientes agrícolas resulta em pressão de seleção nas populações de insetos-praga, o que pode levar à seleção de populações resistentes e acarretar falhas de controle (Bernardi et al., 2015; Head \& Greenplate, 2012). A combinação de diferentes proteínas inseticidas nas culturas agrícolas para o controle de uma praga-alvo pode retardar drasticamente a evolução da resistência pela praga, por requerer que o inseto tenha que desenvolver um mecanismo único de resistência a elas. Estudos mostrando a efetividade de tal estratégia têm confirmado que a combinação de múltiplas proteínas inseticidas na mesma planta, conhecida como piramidação, associada ao plantio das áreas de refúgio, é a estratégia mais efetiva para retardar a evolução da resistência dos insetos (Carrière et al., 2015; Omoto et al., 2015; Roush, 1998; Sheikh et al., 2017; Tabashnik et al., 2013). Storer et al. (2012), estudando resistência de $S$. frugiperda à proteína Cry1F, mencionaram que o uso de duas ou mais proteínas Bt pode retardar o desenvolvimento da resistência, prologando os benefícios e a eficácia dos híbridos de milho com tecnologia $\mathrm{Bt}$, para controle das principais pragas.

O presente trabalho teve por objetivo avaliar a eficácia de híbridos de milho com diferentes proteínas Bt no controle das lagartas $S$. frugiperda e $D$. saccharalis.

\section{Material e Métodos}

Os experimentos foram desenvolvidos na safra 2010/2011, nas estações experimentais da Monsanto do Brasil, em Rolândia-PR (2316'11,6"S; $\left.51^{\circ} 28^{\prime} 48,3^{\prime \prime}\right)$, Não-Me-Toque-RS (28²4'9,4”S; $\left.52^{\circ} 48^{\prime} 18,0^{\prime} \mathrm{W}\right), \quad$ Sorriso-MT $\quad\left(12^{\circ} 25^{\prime} 25,5^{\prime \prime} \mathrm{S}\right.$; $\left.55^{\circ} 38^{\prime} 20,6^{\prime \prime} \mathrm{W}\right)$ e Cachoeira Dourada-MG (18 37'35,4’S; 49²6’20,7'W), sendo que as semea- 
duras foram realizadas em 15/12/2010, 16/12/2010, $14 / 12 / 2010$ e 09/12/2010, respectivamente. Os ensaios foram conduzidos em delineamento experimental de blocos casualizados, com quatro tratamentos (três híbridos Bt e um controle convencional) e quatro repetições. As parcelas foram compostas por seis linhas de milho de 6,0 $\mathrm{m}$ de comprimento, com espaçamento de $0,8 \mathrm{~m}$. A taxa de semeadura foi de 5,5 sementes/m e com população final ao redor de 62.500 plantas/ha. As demais práticas de manejo, como controle fitossanitário e adubação, seguiram as recomendações para a cultura. Não foi realizada a aplicação de inseticidas para controle de pragas.

Foi utilizado o híbrido de milho DKB 390 convencional (não Bt - controle); DKB 390 com o evento MON 810, que expressa a proteína Cry1Ab; DKB 390 com o evento MON 89034, que expressa as proteínas Cry1A.105 e Cry2Ab2; e DKB 390 com o evento MON 89034 × TC1507 × NK603, que expressa as proteínas Cry1A.105, Cry2Ab2 e Cry1F (CTNBio, 2014). A tecnologia MON $89034 \times$ TC1507 × NK603, além de expressar proteínas que promovem o controle de insetos, também apresenta tolerância aos herbicidas glifosato e glufosinato de amônio (proteínas PAT e CP4 EPSPS).

Os tratamentos foram avaliados quanto a injúrias foliares e de colmo, causadas pelas lagartas $S$. frugiperda e D. saccharalis, respectivamente. No primeiro caso, utilizou-se a escala de Davis et al. (1992), com notas de 0 (sem danos visíveis) a 9 (planta completamente destruída). Foram avaliadas 10 plantas por parcela, tomadas ao acaso e em sequência, nos estádios V2-V4, V6-V8, V10-V12 e V14, em que V significa estádio vegetativo, e os números correspondem ao número de folhas completamente expandidas (Ritchie et al., 1993). As injúrias nos colmos foram avaliadas no estádio fenológico R6, que corresponde à maturação fisiológica (Ritchie et al., 1993), em que se procedeu a separação das folhas dos colmos, e em seguida foi realizada a contagem do número de orifícios em 10 colmos tomados ao acaso, por parcela, visualizando os furos ocasionados pela $D$. saccharalis.

O rendimento de grãos $(\mathrm{kg} / \mathrm{ha})$ foi estimado nas plantas das duas linhas centrais da parcela. As espigas foram colhidas manualmente e trilhadas, e o peso foi ajustado para $13 \%$ de umidade.

Os dados foram submetidos ao teste de normalidade e à análise da variância, e as médias foram comparadas pelo teste de Tukey $(\mathrm{p} \leq 0,05)$. Foi realizada a análise de interação entre genótipo e local, configurando-se um fatorial 4 (híbridos) $\times 4$ (locais) (Banzatto \& Kronka, 2006).

\section{Resultados e Discussão}

Embora tenha variado com o local, a incidência de $S$. frugiperda, avaliada pelos índices de injúria às plantas (Davis et al., 1992), permitiu discriminar os tratamentos nas quatro localidades (Tabela 1). Os índices de injúria foram maiores em Não-Me-Toque -RS e em Cachoeira Dourada-MG, apresentando notas mais altas na escala.

Em Sorriso-MT, ocorreu uma baixa infestação de $S$. frugiperda. Os híbridos com eventos piramidados MON 89034 e MON 89034 × TC1507 × NK603, ou seja, com expressão de duas ou mais proteínas $\mathrm{Bt}$ com atividade inseticida para a mesma praga-alvo (Carrière et al., 2015), foram superiores ao não piramidado (MON 810), desde o início da avaliação em V2 até V12.

Em Rolândia-PR, além de baixa infestação, essa foi mais tardia. Apenas a partir de V6-V8 constataram-se injúrias foliares, e os híbridos Bt foram menos atacados que o controle. Em V10-V12, os hí- 
Tabela 1. Injúrias foliares ${ }^{1}$ ocasionadas por S. frugiperda em híbridos de milho em diferentes locais e estádios fenológicos, na safra 2010/2011.

\begin{tabular}{|c|c|c|c|c|}
\hline \multirow{2}{*}{ Genótipo } & \multicolumn{4}{|c|}{ Estádio fenológico } \\
\hline & V2-V4 & V6-V8 & V10-V12 & V14 \\
\hline & \multicolumn{4}{|c|}{ Rolândia-PR } \\
\hline MON 810 & $0,00 \pm 0,00$ & $0,75 \pm 0,25 b$ & $2,25 \pm 0,25 \mathrm{ab}$ & $1,50 \pm 0,29 \mathrm{ab}$ \\
\hline MON 89034 & $0,00 \pm 0,00$ & $0,75 \pm 0,25 \mathrm{~b}$ & $1,25 \pm 0,25 \mathrm{~b}$ & $1,25 \pm 0,25 \mathrm{~b}$ \\
\hline MON $89034 \times$ TC1507 × NK603 & $0,00 \pm 0,00$ & $1,00 \pm 0,00 \mathrm{~b}$ & $1,25 \pm 0,25 \mathrm{~b}$ & $1,50 \pm 0,29 \mathrm{ab}$ \\
\hline \multirow[t]{2}{*}{ Convencional (controle) } & $0,00 \pm 0,00$ & $2,50 \pm 0,25 \mathrm{a}$ & $3,25 \pm 0,29 \mathrm{a}$ & $2,75 \pm 0,48 \mathrm{a}$ \\
\hline & \multicolumn{4}{|c|}{ Não-Me-Toque-RS } \\
\hline MON 810 & $1,63 \pm 0,13 \mathrm{~b}$ & $2,48 \pm 0,28 b$ & $2,58 \pm 0,23 \mathrm{~b}$ & $1,53 \pm 0,10 \mathrm{~b}$ \\
\hline MON 89034 & $0,60 \pm 0,11 \mathrm{c}$ & $1,03 \pm 0,19 \mathrm{c}$ & $0,58 \pm 0,11 \mathrm{c}$ & $1,18 \pm 0,06 \mathrm{~b}$ \\
\hline MON $89034 \times$ TC1507 × NK603 & $0,65 \pm 0,18 \mathrm{c}$ & $1,20 \pm 0,07 \mathrm{c}$ & $0,85 \pm 0,15 \mathrm{c}$ & $1,33 \pm 0,13 \mathrm{~b}$ \\
\hline \multirow[t]{2}{*}{ Convencional (controle) } & $3,38 \pm 0,06 \mathrm{a}$ & $7,21 \pm 0,20 \mathrm{a}$ & $6,25 \pm 0,33 \mathrm{a}$ & $4,70 \pm 0,39 \mathrm{a}$ \\
\hline & \multicolumn{4}{|c|}{ Sorriso-MT } \\
\hline MON 810 & $0,95 \pm 0,03 \mathrm{~b}$ & $1,25 \pm 0,09 \mathrm{~b}$ & $1,43 \pm 0,14 \mathrm{~b}$ & $0,38 \pm 0,24 \mathrm{~b}$ \\
\hline MON 89034 & $0,00 \pm 0,00 \mathrm{c}$ & $0,00 \pm 0,00 \mathrm{c}$ & $0,00 \pm 0,00 \mathrm{c}$ & $0,00 \pm 0,00 \mathrm{~b}$ \\
\hline MON $89034 \times$ TC1507 × NK603 & $0,00 \pm 0,00 \mathrm{c}$ & $0,00 \pm 0,00 \mathrm{c}$ & $0,03 \pm 0,03 \mathrm{c}$ & $0,10 \pm 0,01 \mathrm{~b}$ \\
\hline \multirow[t]{2}{*}{ Convencional (controle) } & $2,05 \pm 0,23 \mathrm{a}$ & $3,03 \pm 0,10 \mathrm{a}$ & $2,63 \pm 0,05 \mathrm{a}$ & $2,53 \pm 0,09 \mathrm{a}$ \\
\hline & \multicolumn{4}{|c|}{ Cachoeira Dourada-MG } \\
\hline MON 810 & $2,50 \pm 0,00 \mathrm{~b}$ & $3,75 \pm 0,00 \mathrm{~b}$ & $1,50 \pm 0,00 \mathrm{~b}$ & $2,25 \pm 0,00 \mathrm{~b}$ \\
\hline MON 89034 & $0,25 \pm 0,00 \mathrm{c}$ & $0,50 \pm 0,00 \mathrm{c}$ & $0,25 \pm 0,00 \mathrm{c}$ & $0,50 \pm 0,00 \mathrm{c}$ \\
\hline MON $89034 \times$ TC1507 × NK603 & $0,50 \pm 0,00 \mathrm{c}$ & $0,00 \pm 0,00 \mathrm{c}$ & $0,00 \pm 0,00 \mathrm{c}$ & $0,25 \pm 0,00 \mathrm{c}$ \\
\hline Convencional (controle) & $6,25 \pm 0,00 \mathrm{a}$ & $6,25 \pm 0,00 \mathrm{a}$ & $4,00 \pm 0,00 \mathrm{a}$ & $4,25 \pm 0,00 \mathrm{a}$ \\
\hline
\end{tabular}

${ }^{1}$ Conforme escala Davis (de 0 a 9).

Médias ( \pm erro padrão) seguidas da mesma letra, nas colunas, não diferem entre si pelo teste de Tukey $(\mathrm{p} \leq 0,05)$.

bridos com eventos piramidados receberam menores notas de injúria em relação ao híbrido não piramidado. Em V14, as injúrias foliares nos híbridos Bt foram semelhantes, diferindo significativamente do híbrido convencional DKB 390 (controle).

Em Cachoeira Dourada-MG e em Não-Me-Toque-RS, foi verificada maior infestação de $S$. frugiperda, evidenciada nas plantas do híbrido convencional DKB 390 (controle), que apresentaram notas da escala de Davis acima de 6 (lesões maiores de 2,5 cm presentes em várias folhas expandidas e novas) e 7 (várias lesões irregulares e algumas áreas das folhas completamente comidas), respectivamente (Tabela 1). Em ambos os locais, os híbridos Bt apresentaram menores notas de injúrias e dessa forma maior proteção ao ataque da praga, em relação ao convencional. Porém, em Cachoeira Dourada-MG, houve diferença entre os híbridos Bt, sendo que os híbridos com eventos piramidados apresentaram melhor eficácia. Em Não-Me-Toque-RS, nas três primeiras avalia- 
ções, as menores injúrias foliares foram observadas nos híbridos com eventos piramidados MON 89034 $\times$ TC1507 × NK603 e MON 89034, diferindo significativamente do híbrido com evento MON 810. O híbrido convencional DKB 390 (controle) apresentou maior injúria, mostrando diferenças significativas entre os híbridos com tecnologia Bt nos quatro tempos de avaliação.

Com relação às injúrias em colmos ocasionadas por D. saccharalis (Tabela 2), os híbridos com tecnologia $\mathrm{Bt}$ foram eficientes no controle desta praga, diferindo significativamente do híbrido convencional nas quatro localidades estudadas. Não se constatou, todavia, diferença entre os eventos Bt. As maiores infestações de $D$. saccharalis foram observadas em Sorriso-MT e a menor infestação foi detectada em Rolândia-PR, sendo que as plantas apresentaram maior e menor número de orifícios em colmos, respectivamente.

Estes resultados corroboram com os obtidos por Michelotto et al. (2011) e Waquil et al. (2013), que encontraram menores injúrias foliares ocasionadas por $S$. frugiperda e menos colmos atacados por $D$. saccharalis em eventos de milho Bt. A piramidação de genes Bt é uma estratégia, além de eficaz no manejo de pragas, interessante no manejo da resistência de insetos, pois espera-se que a frequência de alelos de resistência a um evento de milho contendo duas ou mais proteínas entomotóxicas seja relativamente menor do que na presença de apenas uma proteína $\mathrm{Bt}$ (Waquil et al., 2013).

Mesmo utilizando eventos piramidados, é essencial o monitoramento das populações de insetos-praga nas lavouras e integração de métodos de controle, assim como o plantio de áreas de refúgio, para preservação da eficácia (Manyangarirwa et al., 2006), prolongando os benefícios das tecnologias $\mathrm{Bt}$ aos agricultores.

Com relação ao rendimento de grãos, não houve significância para a interação híbrido e local, mas sim para o efeito dos fatores isolados. Os híbridos com os eventos Bt MON 810, MON 89034 e MON $89034 \times$ TC1507 × NK603 resultaram em maior rendimento de grãos em relação ao híbrido convencional DKB 390 (Figura 1), na ordem de 750 a 900 kg/ha.

Esta diferença de rendimento pode estar associada ao ataque de pragas, dentre elas $S$. frugiperda e D. saccharalis, que provocaram injúrias significativas nas folhas e nos colmos no híbrido convencional. Maior produtividade de milho geneticamente modificado resistente a insetos já foi relatada em outro trabalho (Waquil et al., 2013).

Tabela 2. Número de orifícios ${ }^{1}$ causados por D. saccharalis em colmos de híbridos de milho em diferentes locais, 2010/2011.

\begin{tabular}{lcccc}
\hline \multirow{2}{*}{ Genótipo } & \multicolumn{4}{c}{ Número de orifícios em colmos } \\
\cline { 2 - 5 } & Rolândia- PR & $\begin{array}{c}\text { Não-Me- } \\
\text { Toque-RS }\end{array}$ & Sorriso-MT & $\begin{array}{c}\text { Cachoeira } \\
\text { Dourada-MG }\end{array}$ \\
\hline MON 810 & $0,00 \pm 0,00 \mathrm{~b}$ & $0,00 \pm 0,00 \mathrm{~b}$ & $0,13 \pm 0,09 \mathrm{~b}$ & $0,03 \pm 0,03 \mathrm{~b}$ \\
MON 89034 & $0,00 \pm 0,00 \mathrm{~b}$ & $0,00 \pm 0,00 \mathrm{~b}$ & $0,45 \pm 0,18 \mathrm{~b}$ & $0,00 \pm 0,00 \mathrm{~b}$ \\
MON 89034 $\times$ TC1507 $\times$ NK603 & $0,00 \pm 0,00 \mathrm{~b}$ & $0,00 \pm 0,00 \mathrm{~b}$ & $0,80 \pm 0,08 \mathrm{~b}$ & $0,00 \pm 0,00 \mathrm{~b}$ \\
Convencional (controle) & $0,38 \pm 0,17 \mathrm{a}$ & $1,70 \pm 0,60 \mathrm{a}$ & $3,00 \pm 0,78 \mathrm{a}$ & $1,50 \pm 0,45 \mathrm{a}$ \\
\hline
\end{tabular}

${ }^{1}$ Em 10 plantas/parcela.

Médias ( \pm erro padrão) seguidas da mesma letra, nas colunas, não diferem entre si pelo teste de Tukey $(\mathrm{p} \leq 0,05)$. 


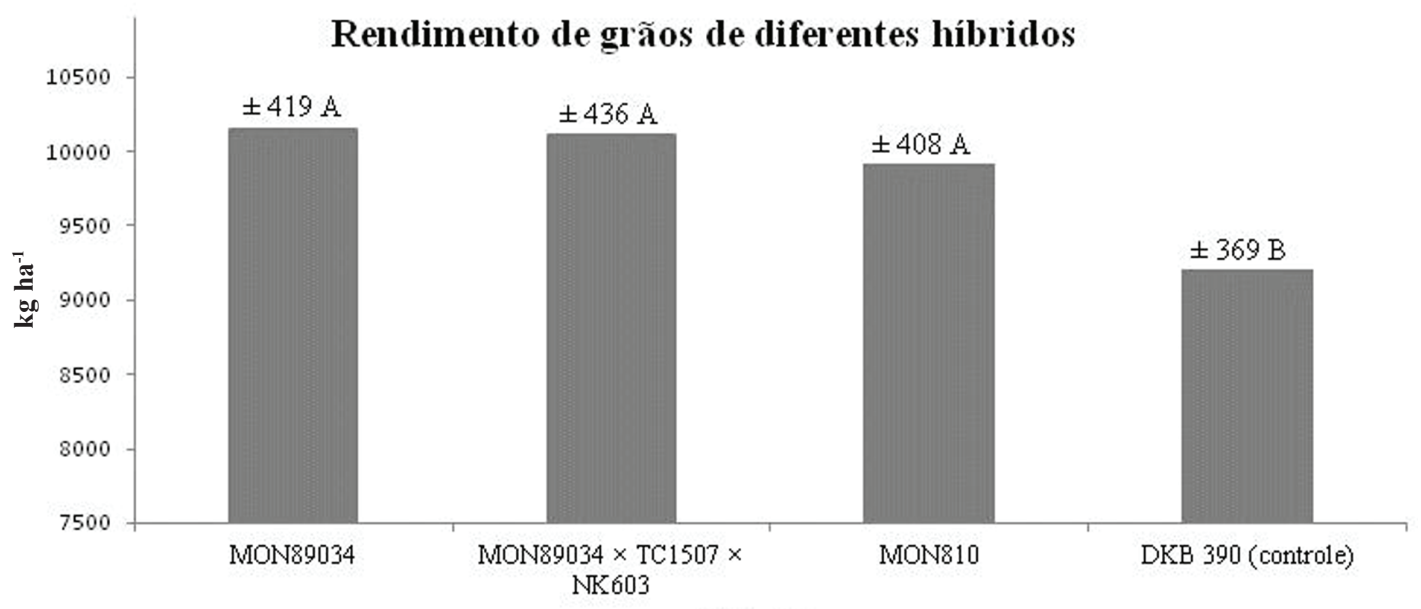

Híbridos

Médias ( \pm erro padrão) seguidas da mesma letra não diferem entre si pelo teste de Tukey ( $\mathrm{p} \leq 0,05)$.

Figura 1. Rendimento de grãos de híbridos de milho frente ao ataque de lagartas de S. frugiperda e de brocas de D. saccharalis (médias de quatro locais: Rolândia-PR, Não-Me-Toque-RS, Sorriso-MT e Cachoeira Dourada-MG, 2010/2011).

\section{Conclusões}

a) Os níveis de injúrias foliares causados por S. frugiperda em milho foram menores nos híbridos geneticamente modificados MON 89034 (Cry1A.105 e Cry2Ab2) e MON 89034 × TC1507 × NK603 (Cry1A.105, Cry2Ab2 e Cry1F) em relação ao híbrido convencional DKB 390, nos quatro locais estudados;

b) O genótipo MON 810 (Cry1Ab) apresentou redução significativa de injúrias de $S$. frugiperda em relação ao híbrido convencional (controle);

c) As injúrias de $D$. saccharalis em colmos de milho foram menores nos híbridos geneticamente modificados MON 89034 (Cry1A.105 e Cry2Ab2), MON $89034 \times$ TC1507 × NK603 (Cry1A.105, Cry2Ab2 e Cry1F) e MON 810 (Cry1Ab) em relação ao híbrido convencional (controle), nos quatro locais estudados;

d) O rendimento de grãos dos híbridos geneticamente modificados MON 89034, MON 89034 ×
TC1507 × NK603 e MON 810 foi maior do que do híbrido convencional (controle).

\section{Agradecimentos}

Agradecemos a contribuição dos pesquisadores Elvio Uzuele, Daniel Sordi, Wagner Motomiya, Patrick Dourado e Diogo Miranda, das Estações Experimentais da Monsanto, pela geração de dados experimentais, e ao Dr. José Magid Waquil, ao Dr. Renato Assis de Carvalho e à Dra. Patrícia Monteiro, pelas críticas e sugestões para a melhoria deste trabalho.

\section{Referências}

BANZATTO, D. A.; KRONKA, S. N. Experimentação agrícola. Jaboticabal: Funep, 2006. 237 p.

BERNARDI, D.; SALMERON, E.; HORIKOSHI, R. J.; BERNARDI, O.; DOURADO, P. M.; CARVALHO, R. A.; MARTINELli, S.; HEAD, G. P.; OMOTO, C. 
Cross-resistance between Cry1 proteins in fall armyworm (Spodoptera frugiperda) may affect the durability of current pyramided Bt maize hybrids in Brazil. PloS One, San Francisco, v. 10, n. 10, p. e0140130, 2015.

DOI: 10.1371/journal.pone.0140130.

CARRIÈRE, Y.; CRICKMORE, N.; TABASHNIK, B. E. Optimizing pyramided transgenic Bt crops for sustainable pest management. Nature Biotechnology, New York, v. 33, p. 161-168, 2015. DOI: 10.1038/nbt.3099.

CRUZ, I. Estratégias de manejo do milho Bt em condições de safrinha. In: SEMINÁRIO NACIONAL DE MILHO SAFRINHA, 10., 2009, Rio Verde. Anais. Rio Verde: Universidade de Rio Verde, 2009. p. 154-170.

CTNBIO. Comissão Técnica Nacional de Biossegurança. Disponível em: $<$ http://ctnbio.mcti.gov.br $>$. Acesso em: 17 jul. 2014.

DAVIS, F. M.; NG, S. S.; WILLIAMS, W. P. Visual rating scales for screening whorl stage corn for resistance to fall armyworm. Mississippi: Agricultural and Forest Experiment Station, 1992. 9 p. (Technical Bulletin, 186).

EDGERTON, M. D.; FRIDGEN, J.;ANDERSON JÚNIOR, J. R.; AHLGRIM, J.; CRISWELL, M.; DHUNGANA, P.; GOCKEN, T.; LI, Z.; MARIAPPAN, S.; PILCHER, C. D.; ROSIELlE, A.; STARK, S. B. Transgenic insect resistance traits increase corn yield and yield stability. Nature Biotechnology, New York, v. 30, p. 493-496, 2012. DOI: $10.1038 /$ nbt.2259.

GALLO, D.; NAKANO, O.; SILVEIRA NETO, S.; CARVALHO, R. P. L.; BAPTISTA, G. C. de; BERTI FILHO, E.; PARRA, J. R. P.; ZUCCHI, R. A.; ALVES, S. B.; VENDRAMIM, J. D.; MARCHINI, L. C.; LOPES, J. R. S.; OMOTO, C. Entomologia agrícola. Piracicaba: FEALQ, 2002. 920 p. (Biblioteca de Ciências Agrárias Luiz de Queiroz, 10).

HEAD, G. P.; GREENPLATE, J. The design and implementation of insect resistance management programs for Bt Crops. GM Crops and Food, v. 3, n. 3, p. 144-153, 2012. DOI: 10.4161/gmcr.20743.
JAMES, C. Global status of commercialized Biotech/GM Crops. Ithaca: International Service for the Acquisition of Ag-biotech Applications, 2014. (ISAAA Brief, 49).

KLÜMPER, W.; QAIM, M. A meta-analysis of the impacts of genetically modified crops. Plos One, San Francisco, v. 9, n. 11, p. 1-7, 2014. DOI: 10.1371/journal.pone.0111629.

LIMA, M. S.; SILVA, P. S. L.; OLIVEIRA, O. F.; SILVA, K. M. B.; FREITAS, F. C. L. Corn yield response to weed and fall armyworm controls. Planta Daninha, Rio de Janeiro, MG, v. 28, p. 103-111, 2010.

DOI: $10.1590 / \mathrm{S} 0100-83582010000100013$.

MANYANGARIRWA, W.; TURNBULL, $\quad$ M.; McCUTCHEON, G. S.; SMITH, J. P. Gene pyramiding as a $\mathrm{Bt}$ resistance management strategy: how sustainable is this strategy? African Journal of Biotechnology, v. 5, n. 10, p. 781-785, 2006.

MiChelOTTO, M. D.; FINOTO, E. L.; DUARTE, A. P. Interação entre transgênicos (Bt) e inseticidas no controle de pragas-chave em híbridos de milho safrinha. Arquivo do Instituto Biológico, São Paulo, v. 78, n. 1, p. 71-79, 2011.

OMOTO, C.; BERNARDI, O.; SALMERON, E.; SORGATTO, R. J.; DOURADO, P. M.; CRIVELLARI, A.; CARVALHO, R. A.; WILLSE, A.; MARTINELLI, S.; HEAD, G. P. Field-evolved resistance to CrylAb maize by Spodoptera frugiperda in Brazil. Pest Management Science, Sussex, v. 72, n. 9, p. 1727-1736, 2015.

DOI: $10.1002 /$ ps.4201.

PINTO, A. S.; PARRA, J. R. P.; OLIVEIRA, H. N. Guia ilustrado de pragas e insetos benéficos do milho e sorgo. Ribeirão Preto: A.S. Pinto, 2004. 108 p.

RITCHIE, S. W.; HANWAY, J. J.; BENSON, G. O. How a corn plant develops. Iowa: Iowa State University, 1993. (Special Report, n. 48).

ROUSH, R. T. Two-toxin strategies for management of insecticidal transgenic crops: can pyramiding succeed where pesticide mixtures have not? Philosophical Transactions of the Royal Society of London. Series B 
. Biological Sciences, London, v. 353, n. 1376, p. $1777-$ 1786, 1998. DOI: 10.1098/rstb.1998.0330.

SANAHUJA, G.; BANAKAR, R.; TWYMAN, R. M.; CAPELL, T.; CHRISTOU, P. Bacillus thuringiensis: a century of research, development and commercial applications. Plant Biotechnology Journal, Oxford, v. 9, n. 3, p. 283-300, 2011.

DOI: 10.1111/j.1467-7652.2011.00595.x.

SHEIKH, A. A.; WANI, A.; BANO, P.; NABI, S. U.; BHAT, T. A.; BHAT, M. A.; DAR, M. S. An overview on resistance of insect pests against Bt crops. Journal of Entomology and Zoology Studies, v. 5, n. 1, p. 941-948, 2017.

STORER, N. P.; KUBISZAK, M. E.; KING, J. E.; THOMPSON, G. D.; SANTOS, A. C. Status of resistance to Bt maize in Spodoptera frugiperda: lessons from Puerto Rico. Journal of Invertebrate Pathology, San Diego, v. 110, n. 3, p. 294-300, 2012.

DOI: 10.1016/j.jip.2012.04.007.
TABASHNIK, B. E.; BRÉVAULT, T.; CARRIÈRE, Y. Insect resistance to $\mathrm{Bt}$ crops: lessons from the first billion acres. Nature Biotechnology, New York, v. 31, p. 510521, 2013. DOI: 10.1038/nbt.2597.

WAQUIL, J. M.; VILLELA, F. M. F.; FOSTER, J. E. Resistência do milho (Zea mays L.) transgênico à lagartado-cartucho, Spodoptera frugiperda (Smith) (Lepidoptera: Noctuidae). Revista Brasileira de Milho e Sorgo, Sete Lagoas, v. 1, n. 3, p. 1-11, 2002.

DOI:10.18512/1980-6477/rbms.v1n3p1-11.

WAQUIL, J. M.; DOURADO, P. M.; CARVALHO, R. A.; OLIVEIRA, W. S.; BERGER, G. U.; HEAD, G. P.; MARTINELLI, S. Manejo de lepidópteros-praga na cultura do milho com o evento piramidado Cry1A.105 e Cry2Ab2. Pesquisa Agropecuária Brasileira, Brasília, DF, v. 48, n. 12, p. 1529-1537, 2013.

DOI: 10.1590/S0100-204X2013001200001. 